\title{
Seven novel species of Acinetobacter isolated from activated sludge
}

\author{
Emma L. Carr, ${ }^{1}$ Peter Kämpfer, ${ }^{2}$ Bharat K. C. Patel, ${ }^{3}$ Volker Gürtler ${ }^{4}$ \\ and Robert J. Seviour ${ }^{1}$ \\ 'Biotechnology Research Centre, La Trobe University, Bendigo, Victoria 3552, Australia \\ ${ }^{2}$ Institut für Angewandte Mikrobiologie, Justus-Liebig-Universität, Giessen D35390, Germany \\ ${ }^{3}$ Faculty of Science and Technology, Griffith University, Nathan, Brisbane, Queensland 4111, \\ Australia \\ ${ }^{4}$ Microbiology Dept, Austin and Repatriation Hospital, Melbourne, Victoria, Australia
}

Correspondence

Emma L. Carr

emma.carr@bendigo.latrobe.

edu.au
Thirteen isolates of Acinetobacter were obtained from activated sludge plants in Victoria, Australia. Earlier 16S-23S rDNA genomic fingerprinting and partial 16S rDNA sequence data had suggested that these isolates might contain previously undescribed species. This view was confirmed here. A polyphasic taxonomic approach involving phenotypic characterization, near-complete 16S rDNA sequence data and DNA-DNA hybridization analyses support the view that seven novel genomic species can be differentiated in this group of isolates. However, when fluorescence in situ hybridization (FISH) studies were performed with a 16S-rRNA-targeted probe specific for the genus Acinetobacter, used to identify Acinetobacter in activated sludge plants, all these strains responded positively. This suggests that these isolates would not have been missed in earlier FISH studies where their role as polyphosphate-accumulating bacteria has been questioned. This report describes these isolates and proposes that they be named Acinetobacter baylyi (type strain B2 ${ }^{\top}=\mathrm{DSM} 14961^{\top}=\mathrm{CIP} 107474^{\top}$ ), Acinetobacter bouvetii (type strain $4 \mathrm{BO} 2^{\top}=\mathrm{DSM} 14964^{\top}=\mathrm{CIP} 107468^{\top}$ ), Acinetobacter grimontii (type strain $17 \mathrm{A0} 4^{\top}=\mathrm{DSM}$ $14968^{\top}=\mathrm{CIP} 107470^{\top}$ ), Acinetobacter tjernbergiae (type strain $7 \mathrm{~N} 16^{\top}=\mathrm{DSM} 14971^{\top}=\mathrm{CIP}$ $107465^{\top}$ ), Acinetobacter towneri (type strain AB1110 ${ }^{\top}=\mathrm{DSM} 14962^{\top}=\mathrm{CIP} 107472^{\top}$ ), Acinetobacter tandoii (type strain $4 \mathrm{~N}_{13} 3^{\top}=\mathrm{DSM} 14670^{\top}=\mathrm{CIP} 107469^{\top}$ ) and Acinetobacter gerneri (type strain $9 \mathrm{A01} 1^{\top}=\mathrm{DSM} 14967^{\top}=\mathrm{CIP} 107464^{\top}$ ).

\section{INTRODUCTION}

Because of their ubiquitous nature and clinical importance, members of the genus Acinetobacter continue to attract interest. Currently, isolates can be confidently and unequivocally assigned to the genus Acinetobacter using the transformation assay of Juni (1972). 16S rDNA sequence analysis has also shown that Acinetobacter spp. represent a well-defined genus (Ibrahim et al., 1997). However, species delineation has been more problematic and although a total of 24 genomic species have so far been recognized, only nine of these have been provided with valid species names (Bouvet \& Grimont, 1986; Nemec et al., 2001). Bouvet \& Grimont (1986) described the first 12 genomic species of

Abbreviations: FISH, fluorescence in situ hybridization; pNA, $p$-nitroanilide; pNP, $p$-nitrophenyl; vsP, variance of separation potential.

The GenBank/EMBL/DDBJ accession numbers for the 16S rDNA sequences of strains $B 2^{\top}, A B 1110^{\top}, 7 N 16^{\top}, 4 B 02^{\top}, 17 A 04^{\top}, 9 A 01^{\top}$ and $4 \mathrm{~N} 13^{\top}$ are AF509820, AF509823, AF509825, AF509827, AF509828, AF509829 and AF509830, respectively.
Acinetobacter, including six that were given valid names, i.e. Acinetobacter calcoaceticus, Acinetobacter baumannii, Acinetobacter haemolyticus, Acinetobacter junii, Acinetobacter johnsonii and Acinetobacter lwoffii. Five additional proteolytic genomic species were subsequently delineated (Bouvet \& Jeanjean, 1989), but none of these were named. Tjernberg \& Ursing (1989) described three more genomic species among their clinical isolates and their DNA group 14 was shown to be identical to genomic species 13 of Bouvet \& Jeanjean (1989). Gerner-Smidt \& Tjernberg (1993) found two additional genomic species that they showed were closely related, but not identical, to the $A$. calcoaceticus- $A$. baumannii complex (Acb complex). Subsequent descriptions of two species, Acinetobacter ursingii and Acinetobacter schindleri, also from clinical sources, were published by Nemec et al. (2001).

While the majority of strains of described species have been isolated from clinical sources, many of the described species also include environmental strains. Overall, the ecology of species belonging to the genus Acinetobacter is not well 
elucidated. Acinetobacter radioresistens isolated from cotton (Nishimura et al., 1988) and an oil-degrading Acinetobacter [invalidly named 'Acinetobacter venetianus' (Di Cello et al., 1997)] represent two of the genomic species of Acinetobacter isolated from environmental sources. Notable among the habitats occupied by Acinetobacter species is activated sludge (Fuhs \& Chen, 1975; Buchan, 1983; Cloete \& Steyn, 1987; Beacham et al., 1990; Knight et al., 1993). Since Acinetobacter spp. were once thought to be responsible for the biological removal of phosphate from wastewater, work has been done looking at isolates from this environment. Molecular probing using fluorescence in situ hybridization (FISH) has suggested that Acinetobacter is not a significant or important phosphate-accumulating bacterial population as only a small percentage could be detected in these systems by FISH with the genus-specific probes described by Wagner et al. (1994) and Snaidr et al. (1997). Furthermore, clone library studies have failed to demonstrate their presence in large numbers in activated sludge systems actively removing phosphorus (Bond et al., 1995, 1999).

Several studies have described strains that could not be identified as known genomic species of Acinetobacter. Even among the clinical isolates characterized to date, some strains in many of the studies have not been assigned to any of the known genomic species (Tjernberg \& Ursing, 1989; Bouvet \& Grimont; 1986; Nishimura et al., 1988; GernerSmidt \& Tjernberg, 1993). The few studies with Acinetobacter isolates from activated sludge have shown repeatedly that many of these do not fit into the already described DNA groups (Maszenan et al., 1997; Carr et al., 2001a, b) and Soddell et al. (1993) concluded that none of the phenotypic identification schemes designed for clinical isolates of Acinetobacter were suitable for their identification. These findings imply that the genus Acinetobacter is much more diverse taxonomically than data from clinical isolates would suggest; this proposal receives support from the work of Carr et al. (2001b), who fingerprinted the 16S-23S rDNA spacer region of Acinetobacter isolates from activated sludge systems in Australia. Results showed that few of these environmental strains grouped closely with the known genomic species. Based on these genomic fingerprints and partial (first $500 \mathrm{bp}$ ) $16 \mathrm{~S}$ rDNA sequences (E. Carr, unpublished data), several of these Acinetobacter strains were selected for further taxonomic study. Phenotypic characteristics and 16S rDNA sequence and DNADNA hybridization data support the view that these strains represent seven novel genomic species of Acinetobacter: Acinetobacter baylyi, Acinetobacter grimontii, Acinetobacter tjernbergiae, Acinetobacter bouvetii, Acinetobacter towneri, Acinetobacter tandoii and Acinetobacter gerneri.

\section{METHODS}

Strains. A total of 13 Acinetobacter strains from activated sludge plants in Victoria, Australia, was selected for systematic studies on the basis of genomic fingerprinting of their 16S-23S rDNA intergenic spacer regions (Carr et al., 2001b). These strains, their sites of isolation and culture collection numbers are given in Table 1. All could be assigned to the genus Acinetobacter by the transformation assay of Juni (1972). The known genomic species used in this study were the type strains described by Bouvet \& Grimont (1986) (denoted BG), Bouvet \& Jeanjean (1989) (denoted BJ), Tjernberg \& Ursing (1989) (denoted TU) and Nemec et al. (2001), which are held at Giessen University by P. Kämpfer. The type strains of the recently described species $A$. ursingii and $A$. schindleri were kindly obtained from M. Vaneechoutte, Belgium. In addition to these activated sludge strains, 198 Acinetobacter strains listed by Gerner-Smidt et al. (1991) were included in the phenotypic section of the work. All these have been previously assigned by them to genomic species of Acinetobacter by DNA-DNA hybridization.

Culture conditions and DNA isolation. All cultures were grown on R2A medium (Reasoner \& Geldreich, 1985) at $30^{\circ} \mathrm{C}$ for $48 \mathrm{~h}$. Chromosomal DNA was extracted from overnight cultures using the Promega Wizard Genomic DNA Purification kit, according to the manufacturer's instructions, resuspended in distilled water, run on an agarose gel to check integrity and then stored at $-20^{\circ} \mathrm{C}$ until used.

Table 1. Details of activated sludge Acinetobacter strains used in this study

\begin{tabular}{|c|c|c|c|c|c|}
\hline $\begin{array}{l}\text { Acinetobacter } \\
\text { strain no. }\end{array}$ & $\begin{array}{c}\text { Biolog } \\
\text { identification }\end{array}$ & $\begin{array}{l}\text { Origin of } \\
\text { isolation }\end{array}$ & $\begin{array}{c}\text { Culture } \\
\text { collection no. }\end{array}$ & $\begin{array}{l}\text { GenBank } \\
\text { acc. no. }\end{array}$ & $\begin{array}{c}\text { Proposed } \\
\text { species name }\end{array}$ \\
\hline $4 \mathrm{~B} 02^{\mathrm{T}}$ & UN & Bendigo, Australia & DSM $14964^{\mathrm{T}}\left(=\mathrm{CIP} 107468^{\mathrm{T}}\right)$ & AF509827 & Acinetobacter bouvetii \\
\hline A7 & UN & Albury, Australia & DSM 14959 (=CIP 107476) & AF509822 & Acinetobacter baylyi \\
\hline C5 & UN & Ballarat, Australia & DSM 14963 (=CIP 107473) & AF509821 & Acinetobacter baylyi \\
\hline $\mathrm{AB} 1110^{\mathrm{T}}$ & BG7 & Bendigo, Australia & DSM $14962^{\mathrm{T}}\left(=\mathrm{CIP} 107472^{\mathrm{T}}\right)$ & AF509823 & Acinetobacter towneri \\
\hline $4 \mathrm{~N} 13^{\mathrm{T}}$ & UN & Bendigo, Australia & $\operatorname{DSM} 14670^{\mathrm{T}}\left(=\operatorname{CIP} 107469^{\mathrm{T}}\right)$ & AF509830 & Acinetobacter tandoii \\
\hline $2 \mathrm{~N} 01$ & BG12 & Bendigo, Australia & DSM 14969 (=CIP 107471) & AF509824 & Acinetobacter towneri \\
\hline $17 \mathrm{~A} 04^{\mathrm{T}}$ & UN & Bendigo, Australia & $\operatorname{DSM} 14968^{\mathrm{T}}\left(=\mathrm{CIP} 107470^{\mathrm{T}}\right)$ & AF509828 & Acinetobacter grimontii \\
\hline $5 \mathrm{~B} 02$ & BG9 & Bendigo, Australia & DSM 14965 (=CIP 107467) & AF509831 & \\
\hline 7B02 & UN & Bendigo, Australia & DSM 14966 (=CIP 107466) & AF509826 & Acinetobacter tjernbergiae \\
\hline
\end{tabular}


PCR amplification and sequencing of 16S rDNA. PCR amplifications of the 16S rDNA were carried out using the universal primers 27F (5'-AGAGTTTGATYMTGGCTCAG-3') and 1525R ( $5^{\prime}$ AGAAAGGAGGTGATCCAGCC-3'), and the PCR protocol of Patel et al. (1995). PCR products were purified using the Concert Rapid PCR Purification system (Life Technologies) and subsequently cloned into the pGEM-T Easy Vector system II (Promega) in accordance with the manufacturers' instructions. Plasmids extracted from the resulting clones using QIAprep Spin Miniprep kits (Qiagen) were digested with EcoRI and run on a $1 \%$ agarose gel to ensure that the plasmid contained the appropriate insert (approx. 1500 bases) before sequencing. All sequencing was carried out with an ABI DNA sequencer model 377a (Applied Biosystems) using Big-Dye Terminator kits (Applied Biosystems).

Phylogenetic analysis of strains. All phylogenetic analysis was carried out using programs available on BioManager by ANGIS (http://www.angis.org.au). The 16S rDNA sequences of the Acinetobacter strains were aligned with $16 \mathrm{~S}$ rDNA sequences of all the known genomic species of Acinetobacter retrieved from GenBank using CLUSTAL W (Thompson et al., 1994). Complete 16S rDNA sequences of $A$. calcoaceticus have been published by two different groups (Rainey et al., 1994; Ibrahim et al., 1997) and both of these sequences were included in the analysis. The $16 \mathrm{~S}$ rDNA sequences of Psychrobacter immobilis and Moraxella lacunata were included as outgroups. The resulting multiple sequence alignment was corrected manually using the program DNASTAR, and approximately 200 bases at the $5^{\prime}$ end of the sequence were omitted from further analysis due to alignment ambiguities. Pairwise evolutionary distances were then computed from a continuous stretch of 1325 bases and a distance matrix was calculated with DNADIST (using the Jukes-Cantor correction parameter). Phylogenetic analysis was carried out by applying the neighbour-joining, parsimony and maximum-likelihood algorithms to ensure coherency of the clusters formed. Bootstrapping was performed (1000 replications) using the SEQBOOT program (Felsenstein, 1989) for the neighbour-joining and parsimony methods to check stability of the clusters formed.

DNA-DNA hybridization. The method used was the nonradioactive colorimetric method described by Ziemke et al. (1998). Comparative DNA-DNA hybridizations were carried out between this method and that described by Grimont et al. (1980) with previously characterized genomic species of Acinetobacter, i.e. A. calcoaceticus ATCC $23055^{\mathrm{T}}$, genomic species 3 (ATCC 19004), A. junii ATCC $17908^{\mathrm{T}}$, A. johnsonii ATCC $17909^{\mathrm{T}}$, genomic species 10 (ATCC 17924) and BG11 (ATCC 11171).

Phenotypic characterization. The type strains of the known genomic species were included in these phenotypic characterizations. All tests were carried out at $30^{\circ} \mathrm{C}$ unless otherwise indicated. Growth at 37, 41 and $44^{\circ} \mathrm{C}$, haemolysis of horse blood and production of acid from glucose were performed as described previously (Bouvet \& Grimont, 1986). Gelatin hydrolysis was carried out using the Microbact 24E identification system (Oxoid). Growth on DL-lactate, DL-4-aminobutyrate, trans-aconitate, citrate, glutarate, aspartate, $\beta$-alanine, L-histidine, D-malate, malonate, histamine, L-phenylalanine, phenylacetate, L-arginine (Bouvet \& Grimont, 1986), L-tryptophan and 4-hydroxybenzoate (Bouvet \& Jeanjean, 1989) was tested using the inorganic medium 'M70' of Veron (1975). All substrates were added at a final concentration of $0 \cdot 1 \%$ $(\mathrm{w} / \mathrm{v})$ and isolates were scored for growth after 2 and 6 days. All strains were also characterized phenotypically using the tests and methods detailed by Kämpfer et al. (1993). In some cases, these tests were the same as those described above and provided a check on the reproducibility of these characterizations. Carbon source assimilation patterns for the activated sludge strains and the known genomic species of Acinetobacter were determined using the Biolog GN Identification system (Oxoid) and these were obtained according to the manufacturer's instructions. Numerical taxonomic analysis of the Biolog data was performed using NTSYS-PC version 1.80 (Exeter software). Tests in which all strains examined were all positive or negative were excluded from this exercise.

Selection of the most discriminatory phenotypic characteristics for identification of strains of Acinetobacter from activated sludge. The activated sludge strains sharing greater than $70.0 \%$ DNA similarity with one another were grouped together and treated as genomic species for selection of the most discriminatory phenotypic tests. The most discriminatory characteristics were selected from the complete matrix of Kämpfer et al. (1993) with the additional data for A. ursingii, A. schindleri and the other activated sludge isolates from this study. These tests were selected from the characteristics used with the CHARSEP program of Sneath (1979a), which determines the value of each characteristic as a potential separator of groups in an identification matrix. From the different separation indices obtained with CHARSEP, the vsP index (variance of separation potential) was then chosen to find those characteristics best able to differentiate between groups. A high vsP index for a particular characteristic indicates its usefulness. For the identification matrix, 32 tests were selected by CHARSEP and further evaluated using DIACHAR software (Sneath, 1980). A theoretical evaluation of the identification matrix was undertaken using MATIDEN (Sneath, 1979b), which calculates an identification score for a set of characteristics based on a Willcox probability score (Willcox et al., 1973).

FISH analysis of Acinetobacter isolates. The two oligonucleotide FISH probes described by Wagner et al. (1994) and Snaidr et al. (1997) for the genus Acinetobacter were tested against these Acinetobacter strains using the same conditions of stringency for each probe as described in the original publications. Pure cultures were fixed in $4 \%$ paraformaldehyde (Amann, 1995) and all subsequent FISH procedures incorporating the appropriate controls were performed according to Amann (1995). Probe EUB 338 of Amann et al. (1990) was used as a positive control to eliminate the possibility of false negative results from problems of probe permeabilities.

\section{RESULTS AND DISCUSSION}

\section{Phylogenetic relationships between Acinetobacter strains using 165 rDNA sequence analyses}

Almost-complete 16S rDNA sequences were acquired for the selected 13 Acinetobacter strains. The overall pattern of clustering seen generally agreed with the clusters obtained for the known genomic species of Acinetobacter by Ibrahim et al. (1997). The groupings of the activated sludge isolates here largely support those revealed from the phenotypic characterization data, in that they usually clustered separately from the described genomic species. For example, strains $17 \mathrm{~A} 04^{\mathrm{T}}$ and $5 \mathrm{~B} 02$ were $98.9 \%$ similar to each other and less than $97 \cdot 0 \%$ similar to all other strains, with the exception of TU13, BG2, BG5 and BJ14, which showed similarity values greater than $97 \cdot 0 \%$. Whereas strains $2 \mathrm{~N} 01$ and $A B 1110^{\mathrm{T}}$ were $97 \cdot 1 \%$ similar to each other, both were less than $97 \cdot 0 \%$ similar to all the other strains. Similarly, strains A7 and C5 were most similar to one another $(98 \cdot 1 \%)$ and, with the exception of strain $\mathrm{B} 2^{\mathrm{T}}$, they were less than $97 \cdot 0 \%$ similar to all other strains. Strain A23 was a distinct entity being less than $97 \cdot 0 \%$ similar to all of the other strains investigated. Strain $4 \mathrm{~N}_{13}{ }^{\mathrm{T}}$ was less than $97 \cdot 0 \%$ similar to all 
of the other strains investigated except BJ15, with which it was $97 \cdot 0 \%$ similar. Strain $9 \mathrm{~A} 01^{\mathrm{T}}$ showed a similarity of less than $97.0 \%$ with all other strains except for the known genomic species BG10, BG11, TU13 and BG5, with which it shared similarity values of $97 \cdot 0,97 \cdot 0,97 \cdot 1$ and $97 \cdot 0 \%$ respectively. Strain $7 \mathrm{~N} 16^{\mathrm{T}}$ was distinct from all other strains except 7B02, with which it was $98 \cdot 2 \%$ similar, whereas 7B02 shared a similarity value of greater than $97 \cdot 0 \%$ with a number of the known genomic species.

The phylogenetic tree (Fig. 1) generated using the maximumlikelihood algorithm reveals the relationships between all these strains. The following clusters were also observed in trees constructed using neighbour-joining and parsimony algorithms (data not shown). Strains $\mathrm{A} 7, \mathrm{C} 5$ and $\mathrm{B} 2^{\mathrm{T}}$ were always linked together, as were strains $5 \mathrm{~B} 02$ and $17 \mathrm{~A} 04^{\mathrm{T}}$, $\mathrm{AB} 1110^{\mathrm{T}}$ and $2 \mathrm{~N} 01$, and $7 \mathrm{~N} 16^{\mathrm{T}}$ and $7 \mathrm{~B} 02$. These clusters were each supported by high bootstrap values. The remainder of the activated sludge strains failed to cluster consistently with any other strains in trees constructed with the three algorithms. For example, with parsimony, strain $4 \mathrm{~B} 02^{\mathrm{T}}$ clustered with $\mathrm{A} 23$ and $4 \mathrm{~N} 13^{\mathrm{T}}$, whereas when the neighbour-joining algorithm was used, $4 \mathrm{~B} 02^{\mathrm{T}}$ emerged as a separate entity, and with maximum-likelihood, it clustered most closely with $A$. schindleri. Strain $9 \mathrm{~A} 01^{\mathrm{T}}$ emerged separately with both maximum-likelihood and neighbourjoining, but linked with $17 \mathrm{~A} 04^{\mathrm{T}}$ and 5B02 after parsimony. Also, strain A23 clustered most closely with $4 \mathrm{~N} 13^{\mathrm{T}}$ with the parsimony and neighbour-joining algorithms. However, this clustering was not supported by high bootstrap values and Fig. 1 shows that both group separately, although A23 was most closely linked to BG10 and BG11.

\section{DNA-DNA hybridization analysis}

By themselves, the $16 \mathrm{~S}$ rDNA sequence comparisons are not sufficiently discriminatory to enable speciation of these Acinetobacter isolates from activated sludge to be determined confidently (Stackebrandt et al., 2002), since the similarity values were in most cases close to $97 \cdot 0 \%$. Therefore DNA-DNA hybridizations were performed between appropriate strains with high $16 \mathrm{~S}$ rDNA sequence similarities. The data (Table 2) clearly indicate that novel genomic species exist within these strains. For example, strains $\mathrm{A} 7, \mathrm{~B}^{\mathrm{T}}$ and $\mathrm{C} 5$ had almost $100 \cdot 0 \%$ mutual DNADNA similarity, but less than $70 \cdot 0 \%$ similarity with any other strain, and therefore represent one novel species. Similarly, strains $7 \mathrm{~N} 16^{\mathrm{T}}$ and $7 \mathrm{~B} 02$ showed a mutual similarity value of $94 \cdot 3 \%$. However, strains $5 \mathrm{~B} 02$ and $\mathrm{A} 23$ shared DNA-DNA similarity values of greater than $70 \cdot 0 \%$ with some known genomic species, with 5B02 emerging as $88 \cdot 1 \%$ similar to A. johnsonii. Strain A23 was $89 \cdot 2 \%$ similar to genomic species 11 and, interestingly, $73.9 \%$ similar to genomic species 10 . The other isolates all had DNA similarities of less than $70.0 \%$ to all other strains, including the known genomic species. Hence, strains $4 \mathrm{~N} 13^{\mathrm{T}}, 17 \mathrm{~A} 04^{\mathrm{T}}$, $9 \mathrm{~A} 01^{\mathrm{T}}$ and $4 \mathrm{~B} 02^{\mathrm{T}}$ are each considered here to represent novel genomic species of Acinetobacter. Hybridizations
P. immobilis ATCC $43116^{\top}$ (U39399)

M. lacunata ATCC $17967^{\top}$ (AF005160)

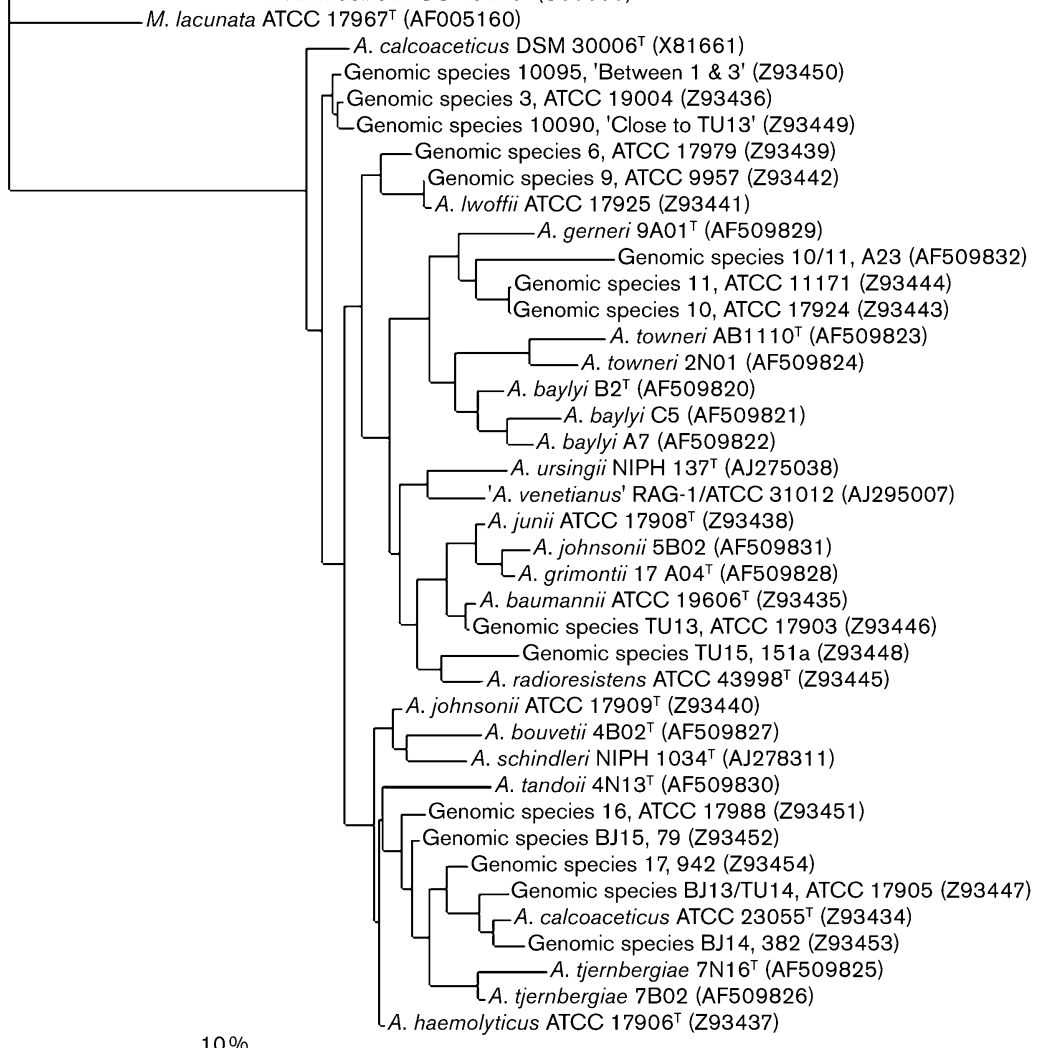

Fig. 1. Phylogenetic tree generated using the maximum-likelihood method of analysis of $16 \mathrm{~S}$ rDNA sequences of Acinetobacter spp. including environmental strains from this study. BJ, genomic species described by Bouvet \& Jeanjean (1989); TU, genomic species described by Tjernberg \& Ursing (1989). The 16S rDNA sequences of Psychrobacter immobilis and Moraxella lacunata were included as outgroups. Bar, $10 \%$ sequence divergence. 


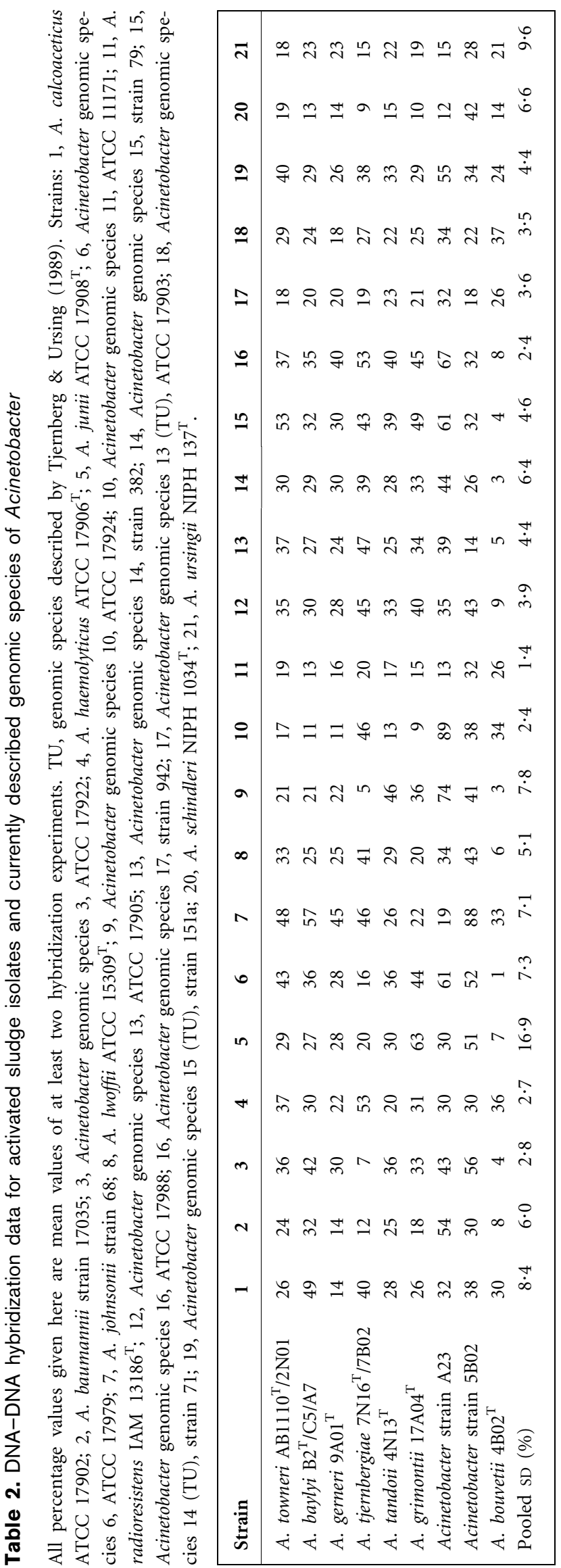

between genomic species 1 and 3, genomic species 5 and 7 , and genomic species 10 and 11 revealed that the protocol of Ziemke et al. (1998) always gave higher values, in some cases by more than $20 \%$, than those obtained with the method of Grimont et al. (1980). For example, in an earlier study by Bouvet \& Grimont (1986), the DNA similarities between genomic species 5 and 7 and genomic species 10 and 11 were shown to be $6-26 \%$ and $22-30 \%$, respectively, whereas in this study the DNA similarities between these groups were shown to be $41 \cdot 5 \%$ (genomic species 5 and 7 ) and $55.6 \%$ (genomic species 10 and 11). The conservative nature of the DNA-DNA hybridization method used in this study has been observed in other studies (Kämpfer et al., 2002). Because this method of DNA-DNA hybridization is more conservative than other methods used in other studies with Acinetobacter (e.g. Bouvet \& Grimont, 1986), there is added confidence in these taxonomic interpretations.

\section{General characteristics of isolates}

All strains were Gram-negative, oxidase-negative, strictly aerobic bacteria. On R2A agar, all grew as coccobacilli in pairs, as expected for members of the genus Acinetobacter. However, in some liquid media, including nutrient broth (Oxoid), morphology was pleiomorphic. For example, in some strains, including 2N01, individual cells appeared as elongated filaments that were sometimes in chains. Strains like $A B 1110^{\mathrm{T}}$, which were originally isolated by micromanipulation from activated sludge as large cell clusters, did not adopt this arrangement in pure culture in liquid or solid media, whereas several others that were not originally isolated as clusters did adopt this arrangement. In others, the individual coccobacilli were in chains, appearing like Eikelboom type 1863 , a morphological form which some Acinetobacter spp. are known to assume in activated sludge plants (Seviour et al., 1997).

\section{Phenotypic characteristics of isolates}

With the phenotypic characterization methods of Kämpfer et al. (1993), all strains tested gave positive results for assimilation of fumarate, L-malate and pyruvate, and all hydrolysed L-alanine- $p$-nitroanilide (L-alanine-pNA). None of the activated sludge isolates haemolysed horse blood, hydrolysed gelatin or grew at $44^{\circ} \mathrm{C}$. None of the strains tested produced acid from D-sucrose, D-mannitol, dulcitol, salicin, D-maltose, D-trehalose, methyl $\beta$-D-xyloside and $m$ erythritol. None grew on D-galactose, D-glucosaminic acid, D-sucrose, D-trehalose, D-turanose, $m$-erythritol, i-inositol, maltitol, L-glycine or L-lysine or hydrolysed p-nitrophenyl- $\beta$-D-galactopyranoside (pNP- $\beta$-D-galactopyranoside), pNP- $\beta$-D-glucuronide, $\mathrm{pNP}-\alpha$-D-glucopyranoside or $\mathrm{pNP}$ $\beta$-glucopyranoside. Variable results were observed for the remainder of the tests.

All of the activated sludge isolates except strains 7B02 and $7 \mathrm{~N} 16^{\mathrm{T}}$ grew at $37^{\circ} \mathrm{C}$. Strains $\mathrm{C} 5, \mathrm{~A} 7$ and $\mathrm{B} 2^{\mathrm{T}}$ were very similar phenotypically except that strain A7 utilized L-histidine and hydrolysed L-proline-pNA, whereas the other two strains did 
not. Strains $2 \mathrm{~N} 01$ and $\mathrm{AB} 1110^{\mathrm{T}}$ also had many phenotypic characteristics in common, with the only differences seen in their abilities to grow on isovalerate, fumarate, DL-malate, L-malate and malonate. Similarly, strains $7 \mathrm{~B} 02$ and $7 \mathrm{~N} 16^{\mathrm{T}}$ shared most phenotypic characteristics.

\section{Identifying these Acinetobacter strains}

Because of their known high level of phenotypic similarity, some genomic species [the $A c b$ complex of 1,2, 3 and 13 (TU), and BG8 and BG9] were grouped together for construction of the identification matrix. On the basis of their vsP index, 32 tests with vsP scores of $64-95 \%$ [far exceeding the $>25 \%$ recommended by Sneath (1979a)] were selected (Table 3). These tests were evaluated with DIACHAR and all 217 strains tested against the identification matrix with MATIDEN. Of these 217 strains, $187(86 \cdot 2 \%)$ were correctly identified with a Willcox probability of more than $99.0 \%$, including all the activated sludge strains characterized here.

\section{Biolog characterization of isolates}

All 13 isolates used Tweens 40 and 80 , methyl pyruvate and succinic acid. None of the 13 strains examined could utilize $m$-inositol, $\alpha$-D-lactose, lactulose, L-fucose, D-psicose, D-raffinose, D-sorbitol, D-trehalose, turanose, xylitol, D-galacturonic acid lactone, D-glucosaminic acid, D-glucuronic acid, L-ornithine, D-serine, L-serine, thymidine, L-alanyl glycine, glycyl-L-aspartic acid, glycyl-Lglutaric acid, inosine, uridine, thymidine, DL- $\alpha$-glycerol phosphate, glucose 1-phosphate or glucose 6-phosphate. All these phenotypic data were subjected to numerical analysis and are represented as a dendrogram (Fig. 2); the activated sludge isolates, with the single exception of strain A23, which groups closely with BG11, appeared to cluster separately from the described genomic species. This is most clearly shown in the case of strains $\mathrm{A} 7, \mathrm{~B}^{\mathrm{T}}$ and $\mathrm{C} 5$. Most of the strains included in this study could not be identified with the Biolog system, repeating the experiences of Knight et al. (1993) with their activated sludge isolates. Good correlation was found between the Biolog GN identification system and the microplate method of Kämpfer et al. (1993) when utilization of the same substrate by the activated sludge strains was tested with both methods. However, small discrepancies were noted. For example, none of the activated sludge strains were shown to assimilate D-mannose using the method of Kämpfer et al. (1993), whereas Biolog showed that strains belonging to A. baylyi gave a positive result for this substrate. Similarly, all strains failed to utilize putrescine by the method of Kämpfer et al. (1993), whereas $4 \mathrm{~N}_{1} 3^{\mathrm{T}}$ gave a positive result with Biolog.

\section{FISH analysis of strains}

The isolation of these previously undescribed genomic species of Acinetobacter from activated sludge systems raised the possibility that the FISH probes currently available for their in situ identification may not embrace these. It was considered possible that quantitative studies on their prevalence in activated sludge using these probes (Wagner et al., 1994; Snaidr et al., 1997) have been underestimating the total numbers of members of this genus. However, when these novel strains were probed with the ACA 23A probe of Wagner et al. (1994), all fluoresced, although not all strains fluoresced with the ACA 652b probe of Snaidr et al. (1997). Hence, theoretically these novel strains would not have been missed in the earlier study of Wagner et al. (1994), which suggested that members of this genus were not participating significantly in the process of microbiological phosphorus removal.

Therefore, this polyphasic approach with strains selected on the basis of their distinctive 16S-23S rDNA intergenic fingerprinting patterns (Carr et al., 2001b) and a combination of phenotypic and genotypic characterization methods, including DNA-DNA hybridization, lends support to the view that strains $\mathrm{AB} 1110^{\mathrm{T}}$ and $2 \mathrm{~N} 01, \mathrm{~B} 2^{\mathrm{T}}, \mathrm{C} 5$ and $\mathrm{A} 7$, and $7 \mathrm{~N} 16^{\mathrm{T}}$ and $7 \mathrm{~B} 02$ are novel genomic species of Acinetobacter. Likewise, all the data presented here provide evidence that $9 \mathrm{~A} 01^{\mathrm{T}}$ and $4 \mathrm{~N} 13^{\mathrm{T}}$ are taxonomically distinct from all other strains investigated. Strain $4 \mathrm{~B} 02^{\mathrm{T}}$ was also shown to represent a novel genomic species according to DNADNA hybridization data. From the 13 activated sludge isolates examined, only two were found to belong to already described genomic species of Acinetobacter. Thus, strain A23 gave a DNA similarity value of greater than $70 \cdot 0 \%$ with both BG10 and BG11, although it showed a higher DNA homology with BG11, agreeing with both the $16 \mathrm{~S}$ rDNA sequence data and the phenotypic data. According to the 16S-23S rDNA spacer region fingerprinting (Carr et al., 2001b), this strain was most similar to BG11. Although strain $5 \mathrm{~B} 02$ was $98.9 \%$ similar to strain $17 \mathrm{~A} 04^{\mathrm{T}}$ after $16 \mathrm{~S}$ rDNA sequence analysis, DNA-DNA hybridization revealed it was greater than $70 \cdot 0 \%$ similar to A. johnsonii. Phenotypic data did not support a close relationship with either strain $17 \mathrm{~A} 04^{\mathrm{T}}$ or $A$. johnsonii. It is interesting that $A$. johnsonii is reportedly unusual among the recognized genomic species of Acinetobacter in being unable to grow at $37^{\circ} \mathrm{C}$ (Bouvet \& Grimont, 1986) yet, in this study, 5B02 was able to do this. Despite this, the DNA-DNA hybridization data mean that 5B02 can be classified as A. johnsonii according to the species definition of Stackebrandt et al. (2002). Strain $17 \mathrm{~A} 04^{\mathrm{T}}$ was also considered to represent a novel species. Hence, on the basis of the data presented here, seven novel species of Acinetobacter are proposed and are described below. In some cases, only single isolates are available for these species. Christensen et al. (2001) have recommended that novel species descriptions should be based on at least five isolates, a recommendation encouraged by Stackebrandt et al. (2002). However, it is felt that this should not be enforced and may not be appropriate for all bacteria. It could markedly reduce effective communication between bacterial systematists since the acquisition of these strains may take considerable time and may never be achieved.

It is clear from other studies that interspecies relationships in the genus Acinetobacter are not clearly defined, as many of 
Table 3. Characteristics $(n=32)$ that differentiate between all the currently described Acinetobacter genomic species and the activated sludge isolates

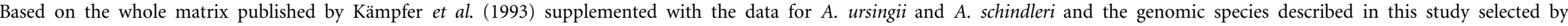

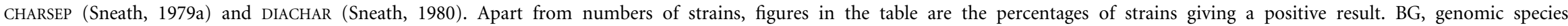

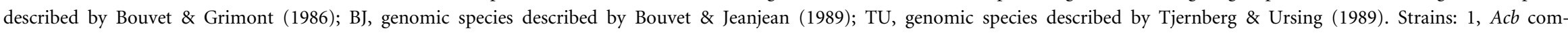

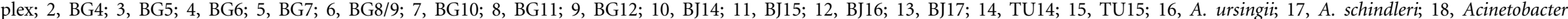
strain 10090; 19, Acinetobacter strain 10095; 20, A7/C5/B2 ${ }^{\mathrm{T}} ; 21, \mathrm{~A} 23 ; 22,9 \mathrm{~A} 01^{\mathrm{T}} ; 23,4 \mathrm{~B} 02^{\mathrm{T}} ; 24,5 \mathrm{~B} 02 ; 25,7 \mathrm{~B} 02 / 7 \mathrm{~N} 16^{\mathrm{T}} ; 26, \mathrm{AB}^{2} 110 / 2 \mathrm{~N}^{\mathrm{T}} 1^{\mathrm{T}} ; 27,17 \mathrm{~A} 04^{\mathrm{T}} ; 28,4 \mathrm{~N} 13^{\mathrm{T}}$.

\begin{tabular}{|c|c|c|c|c|c|c|c|c|c|c|c|c|c|c|c|c|c|c|c|c|c|c|c|c|c|c|c|c|}
\hline Characteristic & 1 & 2 & 3 & 4 & 5 & 6 & 7 & 8 & 9 & 10 & 11 & 12 & 13 & 14 & 15 & 16 & 17 & 18 & 19 & 20 & 21 & 22 & 23 & 24 & 25 & 26 & 27 & 28 \\
\hline Number of strains & 73 & 16 & 21 & 2 & 18 & 23 & 3 & 7 & 22 & 2 & 1 & 1 & 1 & 4 & 2 & 3 & 3 & 1 & 1 & 3 & 1 & 1 & 1 & 1 & 2 & 2 & 1 & 1 \\
\hline \multicolumn{29}{|l|}{ Acid production from: } \\
\hline D-Glucose & 89 & 100 & 5 & 100 & 0 & 43 & 100 & 0 & 77 & 50 & 0 & 100 & 100 & 100 & 100 & 0 & 0 & 100 & 100 & 100 & 0 & 100 & 0 & 0 & 0 & 0 & 0 & 0 \\
\hline Lactose & 88 & 88 & 0 & 100 & 0 & 9 & 67 & 0 & 5 & 50 & 0 & 100 & 100 & 100 & 50 & 0 & 0 & 100 & 100 & 100 & 0 & 100 & 0 & 0 & 0 & 0 & 0 & 0 \\
\hline L-Arabinose & 89 & 100 & 0 & 100 & 11 & 91 & 100 & 0 & 95 & 50 & 0 & 100 & 100 & 100 & 100 & 0 & 0 & 100 & 100 & 100 & 0 & 100 & 0 & 0 & 0 & 0 & 0 & 0 \\
\hline L-Rhamnose & 89 & 62 & 0 & 50 & 0 & 4 & 67 & 0 & 0 & 50 & 0 & 100 & 0 & 0 & 50 & 0 & 0 & 100 & 100 & 100 & 0 & 100 & 0 & 0 & 0 & 0 & 0 & 0 \\
\hline D-Xylose & 89 & 100 & 5 & 100 & 6 & 74 & 100 & 0 & 77 & 50 & 0 & 100 & 100 & 100 & 100 & 0 & 0 & 100 & 100 & 100 & 0 & 100 & 0 & 0 & 0 & 0 & 0 & 0 \\
\hline D-Cellobiose & 89 & 94 & 0 & 100 & 0 & 9 & 67 & 0 & 0 & 50 & 0 & 100 & 100 & 100 & 50 & 0 & 0 & 100 & 100 & 100 & 0 & 100 & 0 & 0 & 0 & 0 & 0 & 0 \\
\hline$\alpha$-D-Melibiose & 89 & 100 & 0 & 100 & 6 & 74 & 100 & 0 & 82 & 50 & 0 & 100 & 100 & 100 & 100 & 0 & 0 & 0 & 0 & 0 & 0 & 0 & 0 & 0 & 0 & 0 & 0 & 0 \\
\hline D-Mannose & 88 & 100 & 0 & 100 & 0 & 48 & 100 & 0 & 55 & 50 & 0 & 100 & 100 & 100 & 100 & 0 & 0 & 100 & 100 & 100 & 0 & 100 & 0 & 0 & 0 & 0 & 0 & 0 \\
\hline \multicolumn{29}{|l|}{ Assimilation of: } \\
\hline Pimelate & 99 & 56 & 57 & 100 & 61 & 91 & 100 & 100 & 100 & 50 & 0 & 100 & 100 & 75 & 100 & 100 & 67 & 100 & 100 & 100 & 100 & 100 & 0 & 0 & 0 & 0 & 0 & 0 \\
\hline cis-Aconitate & 95 & 88 & 14 & 100 & 6 & 0 & 33 & 0 & 0 & 50 & 0 & 100 & 0 & 0 & 0 & 33 & 100 & 100 & 100 & 100 & 100 & 0 & 0 & 0 & 0 & 0 & 0 & 100 \\
\hline trans-Aconitate & 93 & 69 & 0 & 0 & 0 & 0 & 33 & 0 & 0 & 50 & 0 & 0 & 100 & 0 & 0 & 0 & 33 & 100 & 100 & 100 & 100 & 0 & 0 & 0 & 0 & 0 & 0 & 100 \\
\hline Adipate & 97 & 44 & 71 & 100 & 56 & 87 & 67 & 100 & 100 & 50 & 0 & 100 & 100 & 100 & 100 & 100 & 0 & 0 & 100 & 100 & 100 & 100 & 0 & 0 & 0 & 0 & 0 & 0 \\
\hline 4-Aminobutyrate & 100 & 94 & 81 & 50 & 56 & 78 & 67 & 86 & 100 & 50 & 0 & 100 & 0 & 0 & 50 & 0 & 0 & 0 & 0 & 100 & 100 & 100 & 0 & 0 & 0 & 0 & 100 & 100 \\
\hline Azelate & 97 & 0 & 0 & 0 & 17 & 83 & 67 & 100 & 95 & 50 & 0 & 100 & 0 & 0 & 50 & 100 & 67 & 100 & 100 & 100 & 100 & 100 & 0 & 0 & 0 & 0 & 0 & 0 \\
\hline Citrate & 100 & 69 & 48 & 100 & 56 & 9 & 100 & 57 & 0 & 100 & 0 & 100 & 100 & 100 & 0 & 100 & 33 & 100 & 100 & 100 & 100 & 100 & 0 & 100 & 0 & 0 & 100 & 0 \\
\hline Glutarate & 97 & 12 & 14 & 50 & 28 & 26 & 100 & 100 & 100 & 50 & 0 & 100 & 100 & 50 & 50 & 100 & 0 & 100 & 100 & 0 & 100 & 100 & 100 & 0 & 0 & 0 & 0 & 0 \\
\hline Malonate & 92 & 75 & 57 & 100 & 50 & 65 & 0 & 14 & 100 & 100 & 100 & 0 & 100 & 75 & 50 & 0 & 33 & 0 & 100 & 100 & 0 & 0 & 0 & 0 & 0 & 50 & 0 & 100 \\
\hline Oxoisocaprate & 100 & 100 & 33 & 100 & 50 & 22 & 0 & 0 & 100 & 100 & 100 & 100 & 100 & 25 & 0 & 0 & 0 & 100 & 100 & 0 & 0 & 0 & 0 & 0 & 0 & 0 & 0 & 0 \\
\hline Suberate & 100 & 12 & 71 & 50 & 50 & 100 & 100 & 100 & 100 & 50 & 0 & 100 & 0 & 50 & 100 & 100 & 67 & 0 & 100 & 100 & 100 & 100 & 0 & 0 & 0 & 0 & 0 & 0 \\
\hline$\beta$-Alanine & 93 & 6 & 0 & 0 & 0 & 0 & 100 & 100 & 0 & 100 & 100 & 0 & 100 & 50 & 0 & 0 & 0 & 0 & 100 & 0 & 100 & 100 & 0 & 0 & 0 & 0 & 0 & 0 \\
\hline L-Arginine & 100 & 100 & 95 & 100 & 33 & 4 & 0 & 0 & 95 & 100 & 100 & 100 & 100 & 75 & 0 & 0 & 0 & 0 & 0 & 100 & 0 & 0 & 0 & 0 & 100 & 0 & 0 & 100 \\
\hline L-Aspartate & 97 & 38 & 29 & 100 & 61 & 0 & 100 & 100 & 27 & 0 & 0 & 100 & 0 & 50 & 0 & 0 & 0 & 100 & 100 & 100 & 100 & 0 & 0 & 0 & 0 & 0 & 0 & 100 \\
\hline DL-Aspartate & 99 & 6 & 10 & 100 & 44 & 0 & 100 & 86 & 0 & 50 & 0 & 0 & 0 & 0 & 0 & 67 & 100 & 100 & 100 & 100 & 100 & 0 & 100 & 0 & 50 & 0 & 0 & 100 \\
\hline L-Glutamate & 100 & 100 & 100 & 100 & 100 & 39 & 100 & 100 & 100 & 100 & 100 & 100 & 100 & 100 & 50 & 0 & 0 & 0 & 0 & 0 & 0 & 0 & 0 & 0 & 0 & 0 & 0 & 0 \\
\hline L-Histidine & 100 & 100 & 95 & 100 & 0 & 0 & 100 & 100 & 0 & 100 & 100 & 100 & 100 & 100 & 0 & 0 & 0 & 100 & 100 & 33 & 100 & 0 & 100 & 0 & 100 & 0 & 100 & 100 \\
\hline L-Leucine & 99 & 94 & 29 & 100 & 17 & 0 & 0 & 0 & 100 & 100 & 100 & 100 & 100 & 25 & 0 & 0 & 0 & 0 & 100 & 0 & 0 & 0 & 0 & 0 & 0 & 0 & 0 & 0 \\
\hline L-Phenylalanine & 82 & 0 & 0 & 0 & 0 & 0 & 0 & 0 & 100 & 100 & 100 & 100 & 100 & 100 & 50 & 0 & 0 & 100 & 100 & 0 & 0 & 100 & 0 & 0 & 0 & 0 & 0 & 100 \\
\hline L-Tryptophan & 93 & 0 & 0 & 0 & 0 & 0 & 0 & 0 & 14 & 100 & 100 & 0 & 100 & 100 & 0 & 0 & 0 & 100 & 100 & 0 & 0 & 0 & 0 & 0 & 0 & 0 & 0 & 0 \\
\hline L-Leucinamide & 100 & 88 & 10 & 100 & 22 & 0 & 0 & 0 & 100 & 100 & 100 & 0 & 100 & 25 & 0 & 0 & 0 & 0 & 0 & 0 & 0 & 0 & 0 & 0 & 50 & 0 & 0 & 0 \\
\hline 4-Hydroxybenzoate & 95 & 100 & 0 & 50 & 6 & 0 & 67 & 86 & 9 & 100 & 100 & 0 & 100 & 100 & 0 & 100 & 67 & 100 & 100 & 100 & 0 & 100 & 0 & 0 & 0 & 0 & 0 & 0 \\
\hline Phenylacetate & 85 & 0 & 0 & 0 & 0 & 83 & 0 & 71 & 95 & 100 & 100 & 100 & 100 & 100 & 100 & 0 & 0 & 100 & 100 & 100 & 0 & 100 & 0 & 0 & 0 & 0 & 0 & 0 \\
\hline Quinate & 95 & 100 & 0 & 100 & 56 & 0 & 67 & 100 & 0 & 50 & 100 & 100 & 100 & 100 & 0 & 100 & 0 & 0 & 100 & 100 & 100 & 0 & 100 & 0 & 100 & 0 & 0 & 0 \\
\hline
\end{tabular}




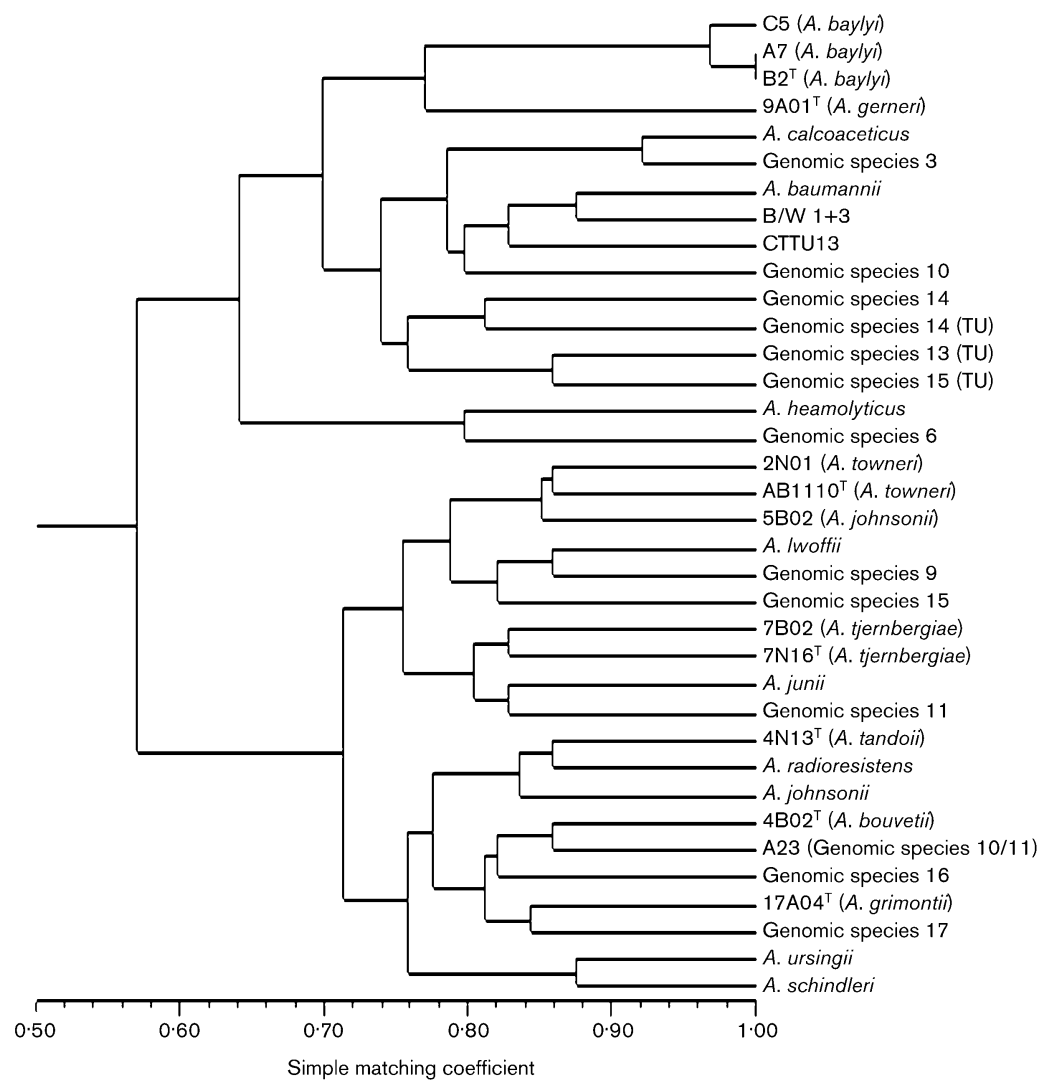

Fig. 2. Dendrogram generated from Biolog data using the UPGMA algorithm as determined by the simple matching coefficient and UPGMA clustering. TU, genomic species described by Tjernberg \& Ursing (1989).

the genomic species are phenotypically very similar to one another and cannot be readily differentiated (Gerner-Smidt et al., 1991). This 'blurring' of speciation complicates species delineation. However, sequencing of appropriate housekeeping genes (Stackebrandt et al., 2002), which ideally requires complete genome sequencing, may assist in this task, but until then attempts to understand the ecology and taxonomy of this organism will continue to frustrate.

It is worthy of mention that these novel strains were all isolated from a very small number of activated sludge plants over a relatively short time period and it is difficult not to conclude that a more extensive search of a larger number of geographically widely distributed plants would reveal many more undescribed members of this genus.

\section{Description of Acinetobacter baylyi sp. nov.}

Acinetobacter baylyi (bay.ly'i. N.L. masc. gen. n. baylyi in honour of Ronald Bayly, an Australian microbiologist who has contributed to the understanding of the physiology of this genus).

Characteristics correspond to those of the genus (Juni, 1984) and colonies on nutrient agar are as described for all other genomic species (i.e. circular, convex, smooth and slightly opaque). Growth occurs at 37 and $41^{\circ} \mathrm{C}$, but not at $44{ }^{\circ} \mathrm{C}$. Acid is produced from D-glucose, horse blood is not haemolysed and gelatin is not hydrolysed. Using the method of Kämpfer et al. (1993), pimelate, cis-aconitate, trans-aconitate, adipate, 4-aminobutyrate, azelate, citrate, malonate, suberate, L-arginine, L-aspartate, DL-aspartate, 4-hydroxybenzoate, phenylacetate and quinate are all utilized, whereas L-histidine is utilized by some strains. Oxoisocaprate, glutarate, $\beta$-alanine, L-glutamate, L-leucine, L-phenylalanine, L-tryptophan and L-leucinamide are not utilized and acid is not produced from $\alpha$-D-melibiose.

The type strain is $\mathrm{B} 2^{\mathrm{T}}$ ( $=$ DSM $14961^{\mathrm{T}}=\mathrm{CIP} 107474^{\mathrm{T}}$ ); it was isolated from activated sludge. This strain does not utilize L-histidine.

\section{Description of Acinetobacter tjernbergiae sp. nov.}

Acinetobacter tjernbergiae (tjern.ber.gi'ae. N.L. fem. gen. n. tjernbergiae in honour of Ingela Tjernberg, a Swedish microbiologist and taxonomist who has contributed to our understanding of the taxonomy of this genus).

Characteristics correspond to those of the genus (Juni, 1984) and colonies on nutrient agar are as described for all other genomic species (i.e. circular, convex, smooth and slightly opaque). No growth occurs at $37^{\circ} \mathrm{C}$ or higher. Acid is not produced from D-glucose, horse blood is not haemolysed and gelatin is not hydrolysed. Using the method of Kämpfer et al. (1993), L-arginine, L-histidine and quinate are all used as sole sources of carbon and energy and some strains utilize DL-aspartate and L-leucinamide. cis-Aconitate, pimelate, trans-aconitate, adipate, 4-aminobutyrate, azelate, citrate, glutarate, malonate, oxoisocaprate, suberate, $\beta$-alanine, L-aspartate, L-glutamate, L-leucine, L-phenylalanine, 
L-tryptophan, 4-hydroxybenzoate and phenylacetate are not utilized.

The type strain is $7 \mathrm{~N} 16^{\mathrm{T}}\left(=\mathrm{DSM} 14971^{\mathrm{T}}=\mathrm{CIP} 107465^{\mathrm{T}}\right)$; it was isolated from activated sludge. This strain does not use DL-aspartate or L-leucinamide.

\section{Description of Acinetobacter towneri sp. nov.}

Acinetobacter towneri (tow.ner'i. N.L. masc. gen. n. towneri in honour of Kevin Towner, an English microbiologist who has contributed to our understanding of the genetics of this genus).

Characteristics correspond to those of the genus (Juni, 1984) and colonies on nutrient agar are as described for all other genomic species (i.e. circular, convex, smooth and slightly opaque). Growth occurs at 37 and $41{ }^{\circ} \mathrm{C}$, but not at $44^{\circ} \mathrm{C}$. No acid production from $\mathrm{D}$-glucose, no haemolysis of horse blood and gelatin is not hydrolysed. Using the method of Kämpfer et al. (1993), DL-lactate and pyruvate are utilized as the sole sources of carbon and energy. Most strains utilize malonate, L-malate, DL-malate, fumarate and isovalerate. Pimelate, cis-aconitate, trans-aconitate, adipate, 4-aminobutyrate, azelate, citrate, glutarate, oxoisocaprate, suberate, $\beta$-alanine, L-arginine, L-aspartate, DL-aspartate, L-glutamate, L-histidine, L-leucine, L-phenylalanine, L-tryptophan, L-leucinamide, 4-hydroxybenzoate, phenylacetate and quinate are not utilized.

The type strain is $\mathrm{AB} 1110^{\mathrm{T}}\left(=\mathrm{DSM} 14962^{\mathrm{T}}=\mathrm{CIP} 107472^{\mathrm{T}}\right)$; it was isolated from activated sludge. This strain utilizes isovalerate, fumarate, DL-malate, L-malate and malonate.

\section{Description of Acinetobacter bouvetii sp. nov.}

Acinetobacter bouvetii (bou.vet.i'i. N.L. masc. gen. n. bouvetii in honour of Philippe Bouvet, a French microbiologist who has contributed to our understanding of the taxonomy of this genus).

Characteristics correspond to those of the genus (Juni, 1984) and colonies on nutrient agar are as described for all other genomic species (i.e. circular, convex, smooth and slightly opaque). Growth occurs at 37 and $41{ }^{\circ} \mathrm{C}$, but not at $44^{\circ} \mathrm{C}$. Acid is not produced from glucose, horse blood is not haemolysed and gelatin is not hydrolysed. Using the method of Kämpfer et al. (1993), glutarate, DL-aspartate, L-histidine and quinate are utilized as sole sources of carbon and energy. Pimelate, cis-aconitate, trans-aconitate, adipate, 4 -aminobutyrate, azelate, citrate, malonate, oxoisocaprate, suberate, $\beta$-alanine, L-arginine, L-aspartate, L-glutamate, L-leucine, L-phenylalanine, L-tryptophan, L-leucinamide, 4-hydroxybenzoate and phenylacetate are not utilized.

The type strain is $4 \mathrm{~B} 02^{\mathrm{T}}\left(=\mathrm{DSM} 14964^{\mathrm{T}}=\mathrm{CIP} 107468^{\mathrm{T}}\right)$; it was isolated from activated sludge.

\section{Description of Acinetobacter grimontii sp. nov.}

Acinetobacter grimontii (gri.mon.ti'i. N.L. masc. gen. n. grimontii in honour of Patrick Grimont, a French microbiologist who has contributed to our understanding of the taxonomy of this genus).

Characteristics correspond to those of the genus (Juni, 1984) and colonies on nutrient agar are as described for all other genomic species (i.e. circular, convex, smooth and slightly opaque). Growth occurs at 37 and $41{ }^{\circ} \mathrm{C}$, but not at $44^{\circ} \mathrm{C}$. Acid is not produced from glucose, horse blood is not haemolysed and gelatin is not hydrolysed. Using the method of Kämpfer et al. (1993), 4-aminobutyrate, citrate and L-histidine are utilized as sole sources of carbon and energy. Pimelate, trans-aconitate, cis-aconitate, adipate, azelate, glutarate, malonate, oxoisocaprate, suberate, $\beta$-alanine, L-arginine, L-aspartate, DL-aspartate, L-glutamate, Lleucine, L-phenylalanine, L-tryptophan, L-leucinamide, 4-hydroxybenzoate, phenylacetate and quinate are not utilized.

The type strain is $17 \mathrm{~A} 04^{\mathrm{T}}\left(=\mathrm{DSM} 14968^{\mathrm{T}}=\mathrm{CIP} 107470^{\mathrm{T}}\right)$; it was isolated from activated sludge.

\section{Description of Acinetobacter gerneri sp. nov.}

Acinetobacter gerneri (ger.ner'i. N.L. masc. gen. n. gerneri in honour of Peter Gerner-Smidt, a Danish microbiologist who has contributed to our knowledge of the taxonomy of this genus).

Characteristics correspond to those of the genus (Juni, 1984) and colonies on nutrient agar are as described for all other genomic species (i.e. circular, convex, smooth and slightly opaque). Growth occurs at 37 and $41^{\circ} \mathrm{C}$, but not at $44^{\circ} \mathrm{C}$. Acid is produced from D-glucose, horse blood is not haemolysed and gelatin is not hydrolysed. Using the method of Kämpfer et al. (1993), pimelate, adipate, 4 -aminobutyrate, azelate, citrate, glutarate, suberate, $\beta$ alanine, L-phenylalanine, L-tryptophan, 4-hydroxybenzoate and phenylacetate are all utilized. cis-Aconitate, transaconitate, malonate, oxoisocaprate, L-arginine, L-aspartate, DL-aspartate, L-glutamate, L-histidine, L-leucine, Lleucinamide and quinate are not utilized.

The type strain is $9 \mathrm{~A} 01^{\mathrm{T}}\left(=\mathrm{DSM} 14967^{\mathrm{T}}=\mathrm{CIP} 107464^{\mathrm{T}}\right)$; it was isolated from activated sludge.

\section{Description of Acinetobacter tandoii sp. nov.}

Acinetobacter tandoii (tan.do'i.i. N.L. masc. gen. n. tandoii in honour of Valter Tandoi, an Italian bacteriologist who has contributed to our understanding of Acinetobacter in activated sludge).

Characteristics correspond to those of the genus (Juni, 1984) and colonies on nutrient agar are as described for all other genomic species (i.e. circular, convex, smooth and slightly opaque). Growth occurs at $37^{\circ} \mathrm{C}$, but not at 41 or $44^{\circ} \mathrm{C}$. Acid is not produced from D-glucose, horse blood is not haemolysed and gelatin is not hydrolysed. Using the method of Kämpfer et al. (1993), cis-aconitate, trans-aconitate, 4-aminobutyrate, malonate, L-arginine, L-aspartate, 
DL-aspartate, L-histidine and L-phenylalanine are all utilized. Pimelate, adipate, azelate, citrate, glutarate, oxoisocaprate, suberate, $\beta$-alanine, L-glutamate, L-leucine, L-tryptophan, L-leucinamide, 4-hydroxybenzoate, phenylacetate and quinate are not utilized.

The type strain is $4 \mathrm{~N} 13^{\mathrm{T}}\left(=\mathrm{DSM} 14670^{\mathrm{T}}=\mathrm{CIP} 107469^{\mathrm{T}}\right)$; it was isolated from activated sludge.

\section{REFERENCES}

Amann, R. I. (1995). In situ identification of microorganisms by whole cell hybridization with rRNA-targeted nucleic acid probes. In Molecular Microbial Ecology Manual, part 3.3.6, pp. 1-15. Edited by A. D. L. Akkermans, J. D. van Elsas \& F. J. de Bruin. Dordrecht: Kluwer Academic.

Amann, R. I., Krumholz, L. \& Stahl, D. A. (1990). Fluorescentoligonucleotide probing of whole cells for determinative, phylogenetic, and environmental studies in microbiology. J Bacteriol 172, 762-770.

Beacham, A. M., Seviour, R. J., Lindrea, K. C. \& Livingston, I. (1990). Genospecies diversity of Acinetobacter isolates obtained from a biological nutrient removal pilot plant of a modified UCT configuration. Water Res 24, 23-29.

Bond, P. L., Hugenholtz, P., Keller, J. \& Blackall, L. L. (1995). Bacterial community structures of phosphate-removing and nonphosphate-removing activated sludges from sequencing batch reactors. Appl Environ Microbiol 61, 1910-1916.

Bond, P. L., Keller, J. \& Blackall, L. L. (1999). Bio-P and non-bio-P bacteria identification by a novel microbial approach. Water Sci Technol 39, 13-20.

Bouvet, P. J. M. \& Grimont, P. A. D. (1986). Taxonomy of the genus Acinetobacter with the recognition of Acinetobacter baumannii sp. nov., Acinetobacter haemolyticus sp. nov., Acinetobacter johnsonii sp. nov., and Acinetobacter junii sp. nov. and emended descriptions of Acinetobacter calcoaceticus and Acinetobacter lwoffii. Int J Syst Bacteriol 36, 228-240.

Bouvet, P. J. M. \& Jeanjean, S. (1989). Delineation of new proteolytic genomic species in the genus Acinetobacter. Res Microbiol 140, 291-299.

Buchan, L. (1983). Possible biological mechanism of phosphorus removal. Water Sci Technol 15, 87-103.

Carr, E., Eason, H., Feng, S., Hoogenraad, A., Croome, R., Soddell, J., Lindrea, K. \& Seviour, R. (2001a). RAPD-PCR typing of Acinetobacter isolates from activated sludge systems designed to remove phosphorus microbiologically. I Appl Microbiol 90, 309-319.

Carr, E., Ward, A., Gürtler, V. \& Seviour, R. J. (2001b). Pyrolysis mass spectrometry (PyMS) and 16S-23S rDNA spacer region fingerprinting suggests the presence of novel acinetobacters in activated sludge. Syst Appl Microbiol 24, 430-442.

Christensen, H., Bisgaard, M., Frederiksen, W., Mutters, R., Kuhnert, P. \& Olsen, J. E. (2001). Is characterization of a single isolate sufficient for valid publication of a new genus or species? Proposal to modify recommendation $30 \mathrm{~b}$ of the Bacteriological Code (1990 Revision). Int J Syst Evol Microbiol 51, 2221-2225.

Cloete, T. E. \& Steyn, P. L. (1987). A combined fluorescent antibodymembrane filter technique for enumerating Acinetobacter in activated sludge. In Biological Phosphate Removal from Wastewaters, pp. 335-338. Edited by R. Ramadori. Oxford: Pergamon Press.
Di Cello, F., Pepi, M., Baldi, F. \& Fani, R. (1997). Molecular characterization of an $\mathrm{n}$-alkane-degrading bacterial community and identification of a new species, Acinetobacter venetianus. Res Microbiol 148, 237-249.

Felsenstein, J. (1989). PHYLIP - Phylogeny inference package (version 3.2). Cladistics 5, 164-166.

Fuhs, G. W. \& Chen, M. (1975). Microbiological basis of phosphate removal in the activated sludge process for the treatment of wastewater. Microb Ecol 2, 119-138.

Gerner-Smidt, P. \& Tjernberg, I. (1993). Acinetobacter in Denmark. II. Molecular studies of the Acinetobacter calcoaceticus-Acinetobacter baumannii complex. Acta Pathol Microbiol Immunol Scand 101, 826-832.

Gerner-Smidt, P., Tjernberg, I. \& Ursing, J. (1991). Reliability of phenotypic tests for identification of Acinetobacter species. J Clin Microbiol 29, 277-282.

Grimont, P. A. D., Popoff, M. Y., Grimont, F., Coynault, C. \& Lemelin, M. (1980). Reproducibility and correlation study of three deoxyribonucleic acid hybridization procedures. Curr Microbiol 4, 325-330.

Ibrahim, A., Gerner-Smidt, P. \& Liesack, W. (1997). Phylogenetic relationship of the twenty-one DNA groups of the genus Acinetobacter as revealed by $16 \mathrm{~S}$ ribosomal DNA sequence analysis. Int J Syst Bacteriol 47, 837-841.

Juni, E. (1972). Interspecies transformation of Acinetobacter: genetic evidence for a ubiquitous genus. J Bacteriol 112, 917-931.

Juni, E. (1984). Genus III. Acinetobacter Brisou et Prévôt 1954. In Bergey's Manual of Systematic Bacteriology, vol. 1, pp. 303-307. Edited by N. R. Krieg \& J. G. Holt. Baltimore: Williams \& Wilkins.

Kämpfer, P., Tjernberg, I. \& Ursing, J. (1993). Numerical classification and identification of Acinetobacter genomic species. J Appl Bacteriol 75, 259-268.

Kämpfer, P., Neef, A., Salkinoja-Salonen, M. \& Busse, H.-J. (2002). Chelatobacter heintzii (Auling et al. 1993) is a later subjective synonym of Aminobacter aminovorans (Urakami et al. 1992). Int J Syst Evol Microbiol 52, 835-839.

Knight, G. C., McDonnell, S. A., Seviour, R. J. \& Soddell, J. A. (1993). Identification of Acinetobacter isolates using the Biolog identification system. Lett Appl Microbiol 16, 261-264.

Maszenan, A. M., Seviour, R. J., McDougall, B. M. \& Soddell, J. A. (1997). Diversity of isolates of Acinetobacter from activated sludge systems based on their whole cell protein patterns. J Ind Microbiol Biotechnol 18, 267-271.

Nemec, A., De Baere, T., Tjernberg, I., Vaneechoutte, M., van der Reijden, T. J. K. \& Dijkshoorn, L. (2001). Acinetobacter ursingii sp. nov. and Acinetobacter schindleri sp. nov., isolated from human clinical specimens. Int J Syst Evol Microbiol 51, 1891-1899.

Nishimura, Y., Ino, T. \& lizuka, H. (1988). Acinetobacter radioresistens sp. nov. isolated from cotton and soil. Int J Syst Bacteriol 38, 209-211.

Patel, B. K. C., Andrews, K. T., Ollivier, B., Mah, R. A. \& Garcia, J. L. (1995). Reevaluating the classification of Halobacteroides and Haloanaerobacter species based on sequence comparisons of the $16 \mathrm{~S}$ ribosomal RNA gene. FEMS Microbiol Lett 134, 115-119.

Reasoner, D. S. \& Geldreich, E. E. (1985). A new medium for the enumeration and subculture of bacteria from potable water. Appl Environ Microbiol 49, 1-7.

Seviour, E. M., Blackall, L. L., Christensson, C., Hugenholtz, P., Cunningham, M. A., Bradford, D., Stratton, H. M. \& Seviour, R. J. 
(1997). The filamentous morphotype Eikelboom type 1863 is not a single genetic entity. J Appl Microbiol 82, 411-421.

Soddell, J. A., Beacham, A. M. \& Seviour, R. J. (1993). Phenotypic identification of non-clinical isolates of Acinetobacter species. J Appl Bacteriol 74, 210-214.

Snaidr, J., Amann, R., Huber, I., Ludwig, W. \& Schleifer, K.-H. (1997). Phylogenetic analysis and in situ identification of bacteria in activated sludge. Appl Environ Microbiol 63, 2884-2896.

Sneath, P. H. A. (1979a). Basic program for character separation indices from an identification matrix of percent positive characters. Comput Geosci 5, 349-357.

Sneath, P. H. A. (1979b). Basic program for identification of an unknown with presence-absence data against an identification matrix of percent positive characters. Comput Geosci 5, 195-213.

Sneath, P. H. A. (1980). Basic program for the most diagnostic properties of groups from an identification matrix of percent positive characters. Comput Geosci 6, 21-26.

Stackebrandt, E., Frederiksen, W., Garrity, G. M. \& 10 other authors (2002). Report of the ad hoc committee for the re-evaluation of the species definition in bacteriology. Int J Syst Evol Microbiol 52, 1043-1047.
Thompson, J. D., Higgins, D. G. \& Gibson, T. J. (1994). CLUSTAL W: improving the sensitivity of progressive multiple sequence alignment through sequence weighting, position-specific gap penalties and weight matrix choice. Nucleic Acids Res 22, 4673-4680.

Tjernberg, I. \& Ursing, J. (1989). Clinical strains of Acinetobacter classified by DNA-DNA hybridization. Acta Pathol Microbiol Immunol Scand 97, 595-605.

Veron, M. (1975). Nutrition et taxonome des Entérobacteriaceae et bacteries voisine I. Méthod d'étude de auxanogrammes. Ann Microbiol (Paris) 126, 267-274.

Wagner, M., Erhart, R., Manz, W., Amann, R., Lemmer, H., Wedi, D. \& Schleifer, K.-H. (1994). Development of an rRNA-targeted oligonucleotide probe specific for the genus Acinetobacter and its application for in situ monitoring in activated sludge. Appl Environ Microbiol 60, 792-800.

Willcox, W. R., Lapage, S. P., Bascomb, S. \& Curtis, M. A. (1973). Identification of bacteria by computer: theory and programming. J Gen Microbiol 77, 317-330.

Ziemke, F., Höfle, M. G., Lalucat, J. \& Rosselló-Mora, R. (1998). Reclassification of Shewanella putrefaciens Owen's genomic group II as Shewanella baltica sp. nov. Int J Syst Bacteriol 48, 179-186. 